\title{
Body composition of adults living with HIV in two cities in Ghana
}

\author{
Theodosia Adom ${ }^{1,}$, , Rose Boatin ${ }^{1}$, David Bansa ${ }^{1}$, Godfred Egbi ${ }^{2}$, Isaac Baidoo ${ }^{3}$, Dominic Datohe ${ }^{1}$, \\ Christian Brown-Appiah ${ }^{1}$
}

${ }^{1}$ Nutrition Research Centre, Radiological and Medical Sciences Research Institute, Ghana Atomic Energy Commission, Legon, Ghana

${ }^{2}$ Nutrition Department, Noguchi Memorial Institute for Medical Research, College of Health Sciences, University of Ghana, Legon, Ghana

${ }^{3}$ Biotechnology and Nuclear Agriculture Research Institute, Ghana Atomic Energy Commission, Legon, Ghana

\section{Email address:}

theo.adom@gmail.com (T. Adom), roseboatin@yahoo.com (R. Boatin), davidbansa@yahoo.com (D. Bansa), GEgbi@noguchi.ug.edu.gh (G. Egbi), baidus@yahoo.com (I. Baidoo), datohe@yahoo.com (D. Datohe), delionbrown@yahoo.com (C. Brown-Appiah)

\section{To cite this article:}

Theodosia Adom, Rose Boatin, David Bansa, Godfred Egbi, Isaac Baidoo, Dominic Datohe, Christian Brown-Appiah . Body Composition of Adults Living with HIV in Two Cities in Ghana. Science Journal of Public Health. Vol. 2, No. 4, 2014, pp. 361-366. doi: 10.11648/j.sjph.20140204.29

\begin{abstract}
Background: Human immunodeficiency virus (HIV) infection affects nutrition through increases in resting energy expenditure, reduction in food intake, nutrient malabsorption and loss, and complex metabolic alterations that culminates in weight loss and wasting common in acquired immune deficiency syndrome. This study sought to assess body composition of adults living with HIV. Methods: This cross-sectional study involved 63 adults living with HIV in two cities in Ghana. Socio-demographic information was obtained with a questionnaire. Body composition was measured with the deuterium dilution method and with anthropometry. Data analysis was done by SPSS version 16.0. Descriptive statistics and frequencies and percentages were calculated. The independent sample t-test was used for comparisons between groups. Differences were considered significant at $\mathrm{p}<0.05$. Results: Median (interquartile range) body mass index was within normal for both males $\left(20.6,\left[18.9,21.6 \mathrm{~kg} / \mathrm{m}^{2}\right]\right)$ and females $\left(21.6 ;\left[19.8,24.9 \mathrm{~kg} / \mathrm{m}^{2}\right]\right)$. Underweight $(7.9 \%)$ and overweight $(19.0 \%)$ were however prevalent. Males have significantly higher median fat free mass than females $(52.7 \mathrm{~kg}$ versus $40.1 \mathrm{~kg} ; \mathrm{p}<0.0001) \mathrm{kg}$ whereas females have a significantly higher fat mass $(27.5 \%$ versus $12.2 \% ; \mathrm{p}<0.0001)$, and high abdominal obesity (49.0\%). Almost $21 \%$ and $8 \%$ of participants have depleted fat free mass and fat mass respectively. Conclusion: The study demonstrates some level of malnutrition among the study participants. This underscores the importance of monitoring body composition in people living with HIV. Measurements of waist and hip circumferences should form part of the assessment tools. This will help in identifying those on antiretroviral treatment that are at risk of developing abdominal obesity and thereby supporting the need for modifying treatment regimens when necessary. In addition, regular screening for hypertension, diabetes and other indicators of metabolic abnormalities is recommended.
\end{abstract}

Keywords: Body Composition, HIV Infection, Deuterium Dilution, Anthropometry, Ghana

\section{Introduction}

Human immunodeficiency virus HIV/acquired immunodeficiency syndrome (AIDS) and malnutrition often operate in tandem. HIV infection affects nutrition through increases in resting energy expenditure, reduction in food intake, nutrients malabsorption and loss, and complex metabolic alterations that culminate in AIDS related weight loss and wasting $[1,2]$.
Weight loss in HIV is generally recognized as an independent predictor of morbidity and mortality. However loss of fat free mass (FFM) is a better predictor of survival [2-5]. The importance of FFM to survival in HIV has led to an increased interest in body composition changes that accompany disease progression [6-8].

Results of body composition studies in HIV infection can serve as a warning sign before wasting sets in [1-2]. The assessment of body composition is as efficient as viral load 
and can provide information on the efficacy of antiretroviral therapy (ART) [7, 9] because some of these drugs increase fat mass leading to insulin resistance [10-11].

Monitoring of the nutritional status of PLHIV is important to ascertain the level of nutrition intervention needed for improvement of their nutritional status. A variety of assessment tools are available to measure body composition in both sick and healthy adults. In developing countries, most of these evaluations have been limited to anthropometric measures such as weight, skinfold thickness, mid-upper-arm circumference (MUAC), waist circumference, and body mass index (BMI).

Incidentally, work done on body composition in Ghana was primarily by the conventional anthropometric methods [12-13]. These methods tend to provide important information on regional fat distribution but are not adequate to detect underlying changes in fat free mass and body fat. Isotopic methods on the other hand give valuable information with more sensitivity and accuracy. Isotopes thus provide a monitoring system to track the rapidly changing HIV/AIDS situation and to initiate timely actions in care, thus slowing down the progress of the disease.

This study sought to address the issue of data paucity on body composition by providing additional information on FM and FFM of PLHIV. The stable isotope deuterium method was used to assess body composition. In addition, the associations among body composition variables measured with anthropometry and deuterium oxide were explored.

\section{Methods}

\subsection{Study Participants and Study Site}

This study was a cross-sectional study involving 63 free living individuals with membership in support groups for PLHIV/AIDS in Accra, the national capital, and Kumasi, capital of the Ashanti Region. Participants were part of a longitudinal study on the use of stable isotopes to assess the impact of food supplements on nutritional status of PLHIV in Ghana.

\subsection{Inclusion Criteria}

Adults aged 18-45 years with CD4 cells counts $\geq 300$ cells $/ \mathrm{mL}$ and willing to participate in the study were recruited. Exclusion criteria included severe malnutrition, pregnancy or lactation, World Health Organisation (WHO) advanced stages (stages III and IV) of the disease and other serious systemic diseases such as cardiovascular disease, diabetes and renal disease. Individuals who were already receiving nutritional support in the form of food supplements were also excluded.

\subsection{Ethical Considerations}

Approval for the study was given by the Ethical Review Committee of the Health Research Unit of the Ghana
Health Service. Prior to enrolment, all persons were informed about the objectives, procedures to be employed and nature of the study after which written informed consent was obtained from each of them. Subjects were informed that participation in the study was voluntary.

\subsection{Procedures}

Socio-demographic information was collected by questionnaires administration. Questions asked include age, level of education, marital status, employment category and status, and household size.

Body weight, height, mid-upper arm circumference (MUAC), waist and hip circumferences and triceps skinfold thickness were measured using standard procedures. Body mass index (BMI) was computed as weight $/$ height $^{2}\left(\mathrm{~kg} / \mathrm{m}^{2}\right)$ and participants classified as: underweight: $<18.5 \mathrm{~kg} / \mathrm{m}^{2}$; normal $18.5-25 \mathrm{~kg} / \mathrm{m}^{2}$; overweight $>25.0 \mathrm{~kg} / \mathrm{m}^{2}$ and $>30$ $\mathrm{kg} / \mathrm{m}^{2}$. Arm fat area (AFA) and arm muscle area in $\mathrm{cm}^{2}$ were calculated using the equation developed by Frisancho [14]. Arm muscle area (AMA) was obtained by subtracting 6.5 for females and 10 for males. Cut-off values of $<32$ $\mathrm{cm}^{2}$ for males and $<18 \mathrm{~cm}^{2}$ for females were used to classify participants. Waist to hip ratio (WHR) was calculated as waist circumference divided by hip circumference. WHR greater than 0.90 for men and 0.85 for women were used to describe abdominal obesity. In addition, male waist circumference $\geq 102 \mathrm{~cm}$ and female waist circumference $\geq 88 \mathrm{~cm}$ are considered unhealthy [15]

Body composition was measured by the deuterium oxide method [16], with Fourier Transform Infrared Spectrometer (FTIR). After a 2 hour fast, basal saliva (pre-dose) was collected from participants into dry, sterile vials and immediately capped. Participants were given a measured dose of deuterium oxide (about $30 \mathrm{~g}$ ) to drink after which the container was rinsed with water. Each participant was asked to drink the water to ensure complete dosing. Post-dose samples were collected after 3 and 4 hours. The samples were kept on ice, transferred to the laboratory and frozen at $-20^{\circ} \mathrm{C}$ prior to analysis. The saliva samples were analysed for deuterium enrichment with the FTIR. Mean enrichment of 3 and 4 hour samples were used to calculate the TBW $(\mathrm{kg})$ from deuterium enrichment at time zero with the use of a correction factor (1.041) for non-aqueous dilution of deuterium oxide. This correction accounts for the exchange of labile hydrogen that occurs in humans during the equilibration period:

(1) Deuterium space $=$ dose ingested $(\mathrm{mg}) \div$ enrichment of deuterium in saliva $(\mathrm{mg} / \mathrm{kg})$

(2) $\mathrm{TBW}(\mathrm{kg})=$ deuterium space $\div 1.041$

(3) FFM $(\mathrm{kg})=\mathrm{TBW}(\mathrm{kg}) \div$ hydration factor $(0.73)$

(4) $\mathrm{FM}=$ Weight $(\mathrm{kg})-$ FFM $(\mathrm{kg})$

The percentage body fat (\%) was calculated as FM $(\mathrm{kg})$ divided by body weight and multiplied by 100 . FM between $25-30 \%$ and $>33 \%$ for females and $15-20 \%$ and $>$ $25 \%$ for males are healthy and obese respectively [17]. Participants are classified as having depleted body reserves when FM and FFM values fall below the healthy range. 
Approximately $5 \mathrm{~mL}$ venous blood was collected in EDTA-containing tubes and transferred to the laboratory for measurement of cell differentiation antigen 4 (CD4 count) using the Guava Easy count machine.

\subsection{Data Analysis}

Data entry was done using SPSS version 16.0. Descriptive statistics (mean, standard deviations, median, interquartile ranges) were calculated for continuous variables while categorical variables were reported as frequencies and percentages. Pearson correlation analyses were conducted to assess the degree of linear relationship between measured variables. The independent sample t-test was used for comparisons between groups. Differences were considered significant at $\mathrm{p}<0.05$.

\section{Results}

This paper discusses the baseline characteristics of 63 participants on the longitudinal study on the use of stable isotopes to assess the impact of food supplements on nutritional status of PLHIV in Ghana.

\subsection{Socio-Demographic Characteristics and Health}

Table 1 summarises the socio-demographic characteristics and health of participants. Participants were asymptomatic at the time of the study. Most of the participants $(77.8 \%)$ are females with majority aged between 31 and 40 years $(66.7 \%)$. Over 30\% participants are either married or widowed. More than $50 \%$ of the participants completed JSS or middle school and $16 \%$ have had primary education. Although a high level of employment was recorded among participants (63.5\%), this was mainly in the informal sector. About 2 out of 3 participants $(67.5 \%)$ have not had any training in employable skills. The majority of participants did not live alone; household size ranged between 3 and 10, with a few $(6.3 \%)$ having more than 10 . Nineteen participants ( 3 males and 16 females, $30.2 \%$ ) reported of illnesses such as fever (47.4\%) and diarrhoea (10.5\%), 2 weeks prior to data collection. Median CD4 cell counts was 485 cells $/ \mathrm{mL}$, similar to median values observed when analysed separately for males $(480[306,880]$ cells/mL and females 485 [291, 793] cells $/ \mathrm{mL})$.

\subsection{Anthropometry and Body Composition}

The anthropometric and body composition data are presented in Table 2.0. Median (interquartile range), weight and height were 58.1 (44.8, 89.1) $\mathrm{kg}$ and 162.3 (149.9, 176.8) cm respectively. Waist circumference, hip circumference, MUAC and triceps were 82.0 (65.9, 103.0) $\mathrm{cm} ; 93.3(82.7,116.0) \mathrm{cm} ; 27.8(22.1,35.7) \mathrm{cm}$, and 11.2 $(3.2,41.1) \mathrm{mm}$. Median BMI for participants was 21.2 $\mathrm{kg} / \mathrm{m}^{2}$ which is within the healthy range. When analysed separately, BMI for males was lower $(20.6$ [18.9, 21.6] $\mathrm{kg} / \mathrm{m}^{2}$ versus $\left.21.6[19.8,24.9] \mathrm{kg} / \mathrm{m}^{2}\right)$. Both BMI and deuterium oxide methods identified $14 \%$ of the males and $6 \%$ females as having reduced body fat. About $25 \%$ females were overweight. Among the male participants, neither overweight nor obesity was recorded (Table 2.0).

Median (IQR) AFA and AMA were $16.3(11.6,25.1) \mathrm{cm}^{2}$ and $37.1(31.9,41.5) \mathrm{cm}^{2}$ respectively among female participants. Median AFA and AMA for males were 7.5 (6.3, 10.1) and $43.1(38.1,50.1) \mathrm{cm}^{2}$. Males had significantly higher AMA $(p<0.0029)$ and females had significantly higher AFA $(\mathrm{p}<0.02)$. High abdominal obesity $(49 \%)$ was observed among female participants compared with $28.6 \%$ among males. However, a relatively small proportion $(22.4 \%)$ has high waist circumference indicative of abdominal obesity and this was observed in females only (Table 2.0).

Table 1.0. Socio-demographic characteristics and health of study participants ${ }^{a}$

\begin{tabular}{|c|c|c|c|}
\hline & Male (n=14) & Female $(n=49)$ & Total $(n=63)$ \\
\hline \multicolumn{4}{|l|}{ Age group } \\
\hline $21-30$ & $0(0.0)$ & $12(28.6)$ & $12(19.0)$ \\
\hline $31-35$ & $4(28.6)$ & $12(24.5)$ & $16(25.4)$ \\
\hline $36-40$ & $6(42.9)$ & $20(40.8)$ & $26(41.3)$ \\
\hline $41-45$ & $4(28.6)$ & $5(10.2)$ & $9(14.3)$ \\
\hline \multicolumn{4}{|l|}{ Marital status } \\
\hline Single & $1(7.1)$ & $8(16.3)$ & $9(14.3)$ \\
\hline Married & $6(42.9)$ & $18(36.7)$ & $24(38.1)$ \\
\hline Widowed & $3(21.4)$ & $17(34.7)$ & $20(31.7)$ \\
\hline Divorced & $2(14.3)$ & $3(6.1)$ & $5(7.9)$ \\
\hline Cohabiting & $2(14.3)$ & $3(6.1)$ & $5(7.9)$ \\
\hline \multicolumn{4}{|l|}{ Level of education } \\
\hline None & $1(7.1)$ & $2(4.1)$ & $3(4.8)$ \\
\hline Primary & $0(0.0)$ & $10(20.4)$ & $10(15.9)$ \\
\hline JSS/Middle & $5(35.7)$ & $31(63.3)$ & $36(57.1)$ \\
\hline SSS & $5(35.7)$ & $3(6.1)$ & $8(12.7)$ \\
\hline Vocational/Secretariat & $2(14.3)$ & $2(4.1)$ & $4(6.3)$ \\
\hline Non formal & $1(7.1)$ & $1(2.0)$ & $2(3.2)$ \\
\hline \multicolumn{4}{|l|}{ Current employment } \\
\hline Employed & $9(64.3)$ & $31(63.3)$ & $40(63.5)$ \\
\hline
\end{tabular}




\begin{tabular}{llll}
\hline & Male $(\mathbf{n}=\mathbf{1 4})$ & Female $(\mathbf{n}=\mathbf{4 9})$ & Total $(\mathbf{n}=\mathbf{6 3})$ \\
\hline $\begin{array}{l}\text { Unemployed } \\
\text { Occupation category }\end{array}$ & $5(35.7)$ & $18(36.7)$ & $23(36.5)$ \\
Salaried workers & & & \\
Semi-skilled workers & $1(11.1)$ & $2(6.5)$ & $3(7.5)$ \\
Unskilled workers & $3(33.3)$ & $7(22.6)$ & $10(25.0)$ \\
Household size & $5(55.6)$ & $22(44.9)$ & $27(67.5)$ \\
Between 2 and 3 & & & $22(34.9)$ \\
Between 4 and 6 & $3(21.4)$ & $19(38.8)$ & $29(46.0)$ \\
Between 7 and 10 & $8(57.1)$ & $21(42.9)$ & $8(12.7)$ \\
More than 10 & $1(7.1)$ & $7(14.3)$ & $4(6.3)$ \\
Illness reported & $2(14.3)$ & $2(4.1)$ & $19(47.4)$ \\
Fever & $3(100)$ & $6(37.5)$ & $2(10.5)$ \\
Diarrhoea & $0(0.0)$ & $2(12.5)$ & $8(42.1)$ \\
Others & $0(0.0)$ & $8(50.0)$ & \\
\hline
\end{tabular}

${ }^{a}$ Results presented as frequency and percentage; ${ }^{\mathrm{b}}$ those employed at the time of the study

Table 2.0. Malnutrition among study participants ${ }^{l}$

\begin{tabular}{llll}
\hline & Male $(\mathbf{n}=\mathbf{1 4})$ & Female $(\mathbf{n}=\mathbf{4 9})$ & Total $(\mathbf{n}=\mathbf{6 3})$ \\
\hline $\begin{array}{l}\text { Body mass index } \\
\text { Underweight }\end{array}$ & $2(14.3)$ & $3(6.1)$ & $5(7.9)$ \\
Overweight & $0(0.00)$ & $12(24.5)$ & $12(19.0)$ \\
Abdominal obesity & & & \\
Waist circumference & $0(0.0)$ & $11(22.4)$ & $11(17.5)$ \\
Waist-to-hip ratio & $4(28.6)$ & $24(49.0)$ & $28(38.1)$ \\
Deuterium oxide method & & $3(6.1)$ & $5(7.9)$ \\
Reduced fat mass & $2(14.3)$ & $13(26.7)$ & $13(20.6)$ \\
Reduced fat free mass & $0(0.0)$ & & \\
\hline
\end{tabular}

${ }^{1}$ Results presented as frequency and percentage

Table 3.0. Anthropometry, fat mass and fat free mass of participants

\begin{tabular}{llll}
\hline & Male $(\mathbf{n}=\mathbf{1 4})$ & Female $(\mathbf{n}=\mathbf{4 9})$ & Total $(\mathbf{n}=\mathbf{6 3})$ \\
\hline Anthropometry & & & \\
Weight $(\mathrm{kg})$ & $61.0(57.1,63.9)$ & $57.9(49.7,63.0)$ & $58.1(50.3,63.5$ \\
Height $(\mathrm{cm})$ & $173.0(169.2,175.2)$ & $160.8(155.8,165.7)$ & $162.3(158.4,169.2)$ \\
BMI $\left(\mathrm{kgm}^{2}\right)$ & $20.6(18.9,21.6)$ & $21.6(19.8,24.9)$ & $21.2(19.8,23.7)$ \\
Waist circum. $(\mathrm{cm})$ & $77.4(73.4,82.7)$ & $82.4(76.6,87.3)$ & $82.0(76.4,85.9)$ \\
Hip circum. $(\mathrm{cm})$ & $92.4(87.9,94.0)$ & $98.8(89.7,102.6)$ & $93.3(89.2,101.1)$ \\
Waist-hip ratio & $0.86(0.82,0.91)$ & $0.85(0.82,0.90)$ & $0.85(0.82,0.90)$ \\
MUAC $(\mathrm{cm})$ & $28.8(26.9,29.6)$ & $27.6(26.3,30.4)$ & $27.827 .4,29.7)$ \\
Triceps (mm) & $5.5(5.0,7.3)$ & $12.4(9.3,19.3)$ & $11.2(7.0,18.1)$ \\
AFA & $7.5(6.3,10.1)$ & $16.3(11.6,25.1)$ & $14.0(9.0,23.9)$ \\
CAMA & $43.1(38.1,50.1)$ & $37.1(31.9,41.5)$ & $37.7(33.7,43.3)$ \\
Deuterium oxide method & & & \\
FFM $(\mathrm{kg})$ & $52.7(51.0,56.4)$ & $40.1(36.8,45.6)$ & $44.2(37.6,48.5)$ \\
FFM $(\%)$ & $87.8(86.6,89.3)$ & $73.0(66.0,77.9)$ & $76.1(68.7,84.2)$ \\
FM (kg) & $7.4(6.0,8.4)$ & $15.5(10.9,21.1)$ & $13.4(9.3,18.7)$ \\
FM $(\%)$ & $12.2(10.7,13.5)$ & $27.5(22.2,34.0)$ & $24.9(15.8,31.3)$ \\
\hline
\end{tabular}

Results presented as median (interquartile range)

\subsection{Associations Among Measured Variables}

Good significant positive correlations were observed between fat free mass and arm muscle area $(r=0.529 ; \mathrm{p}$
$<0.001)$; and between fat mass and arm fat area $(\mathrm{r}=0.767 ; \mathrm{p}$ $<0.001)$. Moreover, there were high positive correlations between percentage fat mass measured with the deuterium oxide method and other indicators of body fat (Table 4.0). 
Table 4.0. Correlation between fat mass, fat free mass and anthropometry

\begin{tabular}{lll}
\hline & FM & FFM \\
\hline Weight & $0.650 ; \mathrm{p}<0.001^{* *}$ & $0.623 ; \mathrm{p}<0.001 *$ \\
Body mass index & $0.861 ; \mathrm{p}<0.001^{* *}$ & $-.0106 ; \mathrm{p}=0.186$ \\
Waist circumference & $0.702 ; \mathrm{p}<0.001^{* *}$ & $0.248 ; \mathrm{p}<0.05^{*}$ \\
Hip circumference & $0.861 ; \mathrm{p}<0.001^{* *}$ & $0.193 ; \mathrm{p}=0.130$ \\
Waist-to-hip ratio & $-0.150 ; \mathrm{p}=0.241$ & $0.060 ; \mathrm{p}=0.639$ \\
Mid upper arm & $0.590 ; \mathrm{p}<0.001^{* *}$ & $0.395 ; \mathrm{p}<0.001 * *$ \\
circumference & $0.761 ; \mathrm{p}<0.001^{* *}$ & $-0.106 ; \mathrm{p}=406$ \\
Triceps & $0.767 ; \mathrm{p}<0.001^{* *}$ & $-0.041 ; \mathrm{p}=0.751$ \\
Arm fat area & $-0.057 ; \mathrm{p}=657$ & $0.529 ; \mathrm{p}<0.001 * *$ \\
\hline Arm muscle area & &
\end{tabular}

**Correlation is significant at the 0.001 level (2-tailed); * Correlation is significant at the 0.05 level (2-tailed

\section{Discussion}

Body composition is important for nutritional studies of HIV infected individuals as an indicator of health and performance status even in the era of ART. Most studies involving the nutritional status of PLHIV in Ghana have been confined to hospitals, particularly the referral hospitals such as Korle-Bu and Komfo Anokye Teaching Hospitals. BMI and skinfold thickness have been the most commonly used conventional methods in majority of these studies. This is one of the first studies that combined anthropometry with deuterium oxide dilution technique to assess body composition among a sample of free living individuals with membership in support groups for PLHIV/AIDS in Ghana.

The deuterium oxide method revealed an overall reduced fat mass and fat free mass among participants. Whereas the BMI did not detect overall obesity, the deuterium oxide method classified 22\% participants as obese. Percent FFM indicative of depleted muscle reserves was recorded in $27 \%$ of only female participants but not with arm muscle area. Similarly depleted fat stores were not detected using arm fat area. However, good significant positive correlations between fat free mass and arm muscle area, and between fat mass and arm fat area observed in the present study is consistent with the literature [18].

Sex differences in the HIV infection and body composition has been documented. Kotler et al [1] have reported females who are HIV negative have more body fat than HIV-positive females while males had more fat free mass than females irrespective of HIV status. Females in the present study generally tend to be heavier compared to their height with significant high fat mass. This is consistent with the observation in a sample of Ghanaian adults living with HIV [19]. Compared to the report of Visnegarwala [20] however, participants in the current study have reduced fat mass and fat free mass.

Waist circumference and waist-hip ratio increase with the accumulation of visceral fat in individuals with or without HIV infection $[1,25]$. In healthy populations this has been attributed to dietary intake [25] whereas in HIV positive individuals on Highly Active Antiretroviral Therapy (HAART) abdominal fat deposition has been identified as a common morphological alteration. A high proportion of participants in the present study have developed abdominal obesity. This mirrors findings reported elsewhere [21-22]. The trend predisposes participants in the present study to cardiometabolic complications [23] in addition to the known health complications associated with the infection.

There is evidence to suggest that the high WHR in PLHIV who are on ART is due to prescription of protease inhibitors resulting in decreased hip circumference as opposed to faster fat deposition in the waist [24]. ART regimen used in Ghana is based on the HAART involving triple drug therapy but no quantitative data on duration and specific drugs was collected in the present study. However two-thirds of participants in the present study were on ART. The inverse association observed suggests that those on ART have increasing waist-to-hip ratio, and waist circumference as opposed to those not on ART since no such association was observed with dietary intake [26].

\section{Conclusion}

The study demonstrates some level of malnutrition among the study participants. Depleted FFM and FM were observed. The incidence of abdominal obesity was high especially among females. This study underscores the importance of body composition as a measure for monitoring changes in PLHIV. It is recommended that measurements of waist and hip circumferences should form part of the assessment tools used in monitoring PLHIV to help in identifying those on ART therapy that are at risk of developing abdominal obesity. This may be helpful in modifying treatment regimens when necessary. In addition, regular screening for hypertension and diabetes is recommended.

It is recommended that simpler field techniques such as anthropometry and bioelectrical impedance technique that are already being used in body composition studies be validated with the deuterium oxide method, which is more sensitive and accurate to detect changes in fat mass and fat free mass.

\section{Acknowledgements}

The authors are grateful to all the support groups of people living with HIV/AIDS that participated in the study as well as individuals who agreed to be part of the study. The International Atomic Energy Agency provided technical support in the execution of this project on the regional project RAF7006.

\section{References}

[1] Kotler DP, Rosenbaum K, Wang J, Pierson RN. Studies of body composition and fat distribution in HIV-infected and control subjects. J Acquir Immune Defic Syndr Hum Retrovirol 1999; 20: 228-37 
[2] Tang AM, Graham NM, and Saah AM. Effects of micronutrient intake on survival in human immunodeficiency virus type 1 (HIV-1) infection. Am J Epidemiol 1996; 143: 1244-1256.

[3] Kotler DP, Tierney AR, Wang J, et al. Magnitude of body cell mass depletion and timing of death from wasting in AIDS. Am. J. Clin. Nutr. 1989; 50: 444-7.

[4] Wheeler DA, Gilbert CL, Launer CA. et al, Weight loss as a predictor of survival and disease progression in HIV infection. J Acquir Immuno Defic Syndr. 1998; 18: 80-85.

[5] Macallan DC. Wasting in HIV infection and AIDS. J Nutr 1999; 129: 238S-242S.

[6] Forrester JE, Spiegelman D, Woods M, Knox TA, Fauntleroy JM, Gorbach SL. Weight and body composition in a cohort of HIV-positive men and women. Public Health Nutrition 2001: 4(3), 743-747.

[7] Ferrando SJ, Rabkin JG, Lin SH, McElhiney M. Increase in body cell mass and decrease in wasting are associated with increasing potency of antiretroviral therapy for HIV infection. AIDS Patient Care STDS. 2005 19(4): 216-26.

[8] Degris E, Delpierre C, Sommet A, et al. Longitudinal study of body composition of 101 HIV men with lipodystrophy: dual-energy X-ray criteria for lipodystrophy evolution. J. Clin Densitom. 201013 (2):237-44. Epub 2010.

[9] McDermott AY, Terrin N, Wanke C, Skinner S, Tchetgen E, Shevitz AH. CD4+ cell count, viral load, and highly active antiretroviral therapy use are independent predictors of body composition alterations in HIV-Infected adults: a longitudinal study. Clinical Infectious Diseases 2005; 41:1662-70.

[10] Jones CY, Wilson IB, Greenberg AS, Shevitz A, et al. Insulin Resistance in HIV-Infected Men and Women in the Nutrition for Healthy Living Cohort. J Acquir Immune Defic Syndr 2005; 40 (5): 565-572

[11] Lo, JC, Kazemi MR, Hsue PY, Martin JN, Deeks SG, Schambelan M, Mulligan $\mathrm{K}$. The relationship between nucleoside analogue treatment duration, insulin resistance, and fasting arterialized lactate level in patients with HIV infection. Clin Infect Dis 2005; 41:1335-40.

[12] Afoakwa AN, Owusu WB. The relationship between dietary intake, body composition and blood pressure of male adult miners in Ghana. Asian J Clin Nutr. 2011; 3(1): 1-13.

[13] Laar AK, Owusu WB, Yeboah K. Anthropometric characteristics of HIV/AIDS patients in Accra, Ghana. J Ghana Sci Assoc. 2004. 6(1): 1-7.
[14] Frisancho AR. New norms of upper limb fat and muscle areas for assessment of nutritional status. Am J Clin Nutr $1981 ; 34: 2540-5$.

[15] World Health Organization. Waist circumference and waist-hip ratio: report of a WHO expert consultation, Geneva, 8-11, December 2008. WHO 2011

[16] Jennings G, Bluck L, Wright A, Elia M. The use of infrared spectrophotometry for measuring body spaces. Am J Clin Nutr 1999; 45: 1077-1081.

[17] Wilmore JH, Buskirk ER, DiGirolamo M, and Lohman TG. Body Composition: A round table. The Physician and Sportsmedicine, 1986; 14(3), 144-162.

[18] Lee RD and Nieman DC. Nutritional Assessment 3rd edition, New York, USA, McGraw Hill; 2003

[19] Wiig K and Smith C. An exploratory investigation of dietary intake and weight in human immunodeficiency virus-seropositive individuals in Accra, Ghana. J Am Diet Assoc 2007; 107: 1008-13.

[20] Visnegarwala F, Raghavan SS, Mullin CM, Bartsch G, Wang J, Kotler D, et al. Sex differences in the associations of HIV disease characteristics and body composition in antiretroviral naive persons. Am J Clin Nutr 2005; 82: $850-6$.

[21] Hejazi N, Lee MHS, Lin KG, Choong CLK. Factors Associated with abdominal obesity among HIV-infected adults on antiretroviral therapy in Malaysia. Global Journal of Health Science 2010; 2 (2); 20-31.

[22] Jaime, PC, Florindo, AA, Latorre, MDo R, and Segurado, AA. Central obesity and dietary intake in HIV/AIDS patients. Rev Saúde Pública, 2006; 40 (4), 634-40.

[23] Hadigan C, Meigs JB, Corcoran C, et al. Metabolic abnormalities and cardiovascular disease risk factors in adults with human immunodeficiency virus infection and lipodystrophy. Clin Infect Dis 2001; 32:130-9.

[24] Florindo, AA, Latorre Mdo, R, Santos, EC, Borelli, A, Rocha Mde, S, Segurado, AA. Validation of methods for estimating HIV/AIDS patients' body fat. Revista de Saúde Pública, 2004; 38 (5), 643-649.

[25] World Health Organization - WHO. Diet, nutrition and the prevention of chronic diseases. Report. Geneva; 2003. [WHO Technical Report Series, 916]

[26] Adom T, Boatin R, Bansa D, et al. Use of isotopes to assess the impact of food supplements on nutritional status of people living with HIV/AIDS in Ghana, unpublished. 